\title{
Penerapan Algoritma Greedy Dalam pencarian Jalur Terpendek pada Masjid-Masjid di Kota Samarinda
}

\author{
Fariszal Nova Arviantino ${ }^{1 *}$, Windu Gata ${ }^{2}$, Laela Kurniawati ${ }^{3}$, Yusuf Arif Setiawan ${ }^{4}$, Dedi Priansyah ${ }^{5}$ \\ ${ }^{12345}$ Program Studi Magister Ilmu Komputer STMIK Nusa Mandiri Jakarta
}

*fariszalnova05@gmail.com

\begin{abstract}
The search for the shortest path to mosques in the city of Samarinda is very much needed by clerics, clerics and scholars who want to hold preaching safaris. In addition, relevant agencies such as the ministry of religion are also required to make visits with the aim of collecting data on mosques. The greedy algorithm works by finding the smallest weight point by calculating the path that is passed and depending on the weight of the stages that have been passed and the weight of the stage itself. This study tested the greedy algorithm at 7 mosques in downtown Samarinda which were frequently visited for preaching safaris and other activities.
\end{abstract}

Keyword: shortest path search, mosque, greedy algorithm

\begin{abstract}
Abstrak
Pencarian jalur terpendek pada masjid-masjid di kota Samarinda sangat diperlukan oleh ustadz, kyai maupun ulama yang ingin mengadakan safari dakwah. Selain itu juga diperlukan oleh instansi terkait seperti kementerian agama yang ingin melakukan kunjungan dengan tujuan pendataan masjid. Algoritma greedy bekerja dengan menccari titik bobot yang terkecil dengan menghitung jalur yang dilewati dan tergantung dari bobot tahapan yang telah dilewati serta bobot pada tahap itu sendiri. Penelitian ini menguji algoritma greedy pada 7 masjid di tengah kota Samarinda yang sering dikunjungi untuk safari dakwah maupun aktivitas lainya.
\end{abstract}

Kata kunci: pencarian jalur terpendek, masjid, algoritma greedy

\section{Pendahuluan}

Samarinda merupakan ibukota provinsi Kalimantan timur, Negara Kepualauan Republik Indonesia. Dengan komposisi masyarakat sebagian besar adalah muslim membuat jumlah masjid yang ada di kota Samarinda sangat banyak. Hal ini dibuktikan dengan adanya 125 lebih masjid yang sudah terilis pada google maps (data 4 desember 2020). Dengan penduduk mayoritas muslim tersebut, tidak di pungkiri akan banyaknya aktivitas dakwah pada masjid masjid yang ada di kota Samrinda. Dalam melakukan safari dakwah maupun kunjungan ke masjid-masjid dalam rangka pendataan, maka diperlukanya suatu perhitungan sistematis agar kunjungan ke masjid-masjid yang ada di kota Samarinda menjadi efektif dengan mencari rute terdekat dari satu titik ke titik selanjutnya dan menghabiskan waktu yang relatif sedikit.
Algoritma Greedy merupakan suatu algoritma yang memiliki metode pendekatan untuk membangun solusi optimal dengan mencari rute perjalanan terpendek dengan waktu yang optimum [1]. Greedy memberikan alternatif optimum lokal dengan harapan setiap alternatif lokal menghasilkan alternatif optimum global yang optimal secara keseluruhan[2].

Algoritma greedy adalah algoritma yang memecahkan masalah langkah demi langkah, pada setiap langkah[3]:

a. Mengambil pilihan yang terbaik yang dapat diperoleh saat itu.

b. Berharap bahwa dengan memilih optimum lokal pada setiap langkah akan mencapai optimum global. Algoritma greedy mengasumsikan bahwa optimum lokal merupakan bagian dari optimum global. 


\section{Metoda Penelitian}

Metoda yang dipakai dalam penelitian ini berupa langkah kerja serta rangkaian kegiatan secara berurutan sebagai berikut :

a. Penentuan masjid-masjid yang akan dikunjungi.

b. Penentuan waktu singgah pada tiap tiap masjid.

c. Pencarian rute tercepat menggunakan algoritma greedy.

d. Perhitungan jumlah waktu perjalanan dan waktu singgah pada masjid secara keseluruhan.

\subsection{Pengumpulan Data}

Penelitian ini diawali dengan tinjauan pustaka serta pengumpulan data primer. Pada tahap ini peneliti menentukan titik lokasi masjid-masjid yang akan dikunjungi. Peneliti berfokus pada masjid di tengah Kota Samarinda dan mengambil 7 masjid yang sering dikunjungi untuk aktivitas safari dakwah maupun tujuan lainya. Ketujuh masjid ini adalah:

A. Masjid Al Khairiyah

B. Masjid Al Muaawanah

C. Masjid Syeikh Mahmudin

D. Masjid Maninjau

E. Masjid Al Khair

F. Masjid Al Ma'aruf

G. Masjid Islamic Center

Yang selanjutnya titik titik tersebut dihubungkan membentuk suatu graf. Saat menggambar graf kita menghubungankan beberapa simpul dengan lintasan terpendek berdasarkan waktu tempuh perjalanan[5]. Graf yang digunakan dalam penelitian ini adalah graf berbobot ( weight graph), yaitu graf yang setiap sisinya diberikan suatu nilai atau bobot, dalam hal ini bobot adalah waktu tempuh antar titik[5].

Penentuan titik awal dalam perjalanan ini dimulai dari titik A yaitu pada masjid $\mathrm{Al}$ Khairiyah.

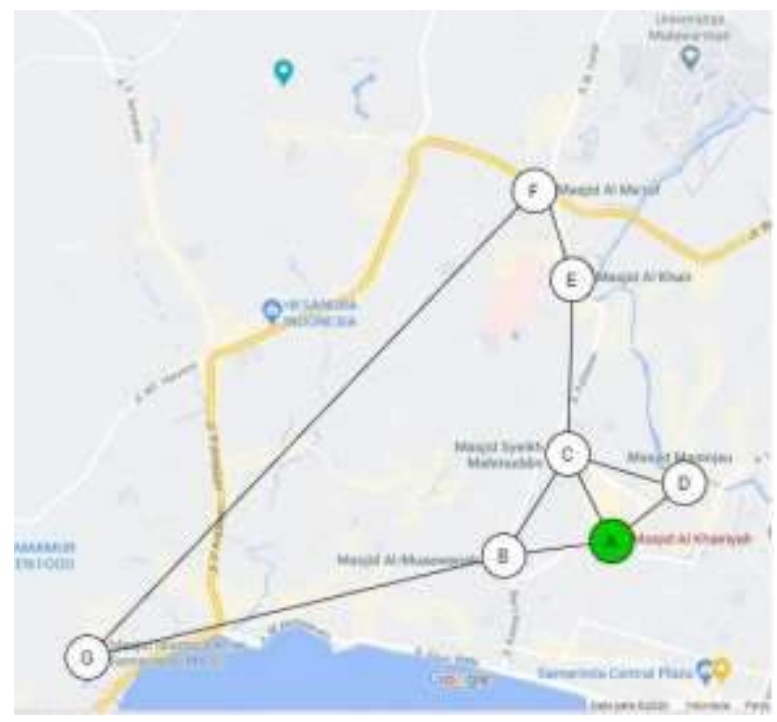

Gambar 1. Graf pada Titik masjid yang akan dikunjungi

Selanjutnya pengumpulan data sekunder yaitu pada tahapan ini peneliti melakukan perhitungan waktu tempuh antar titik graf yang disesuaikan dengan waktu tempuh pada google maps. Setelah mendapatkan waktu tempuh antar titik dalam graf, selanjutnya data dimasukan dalam graf penghubung.

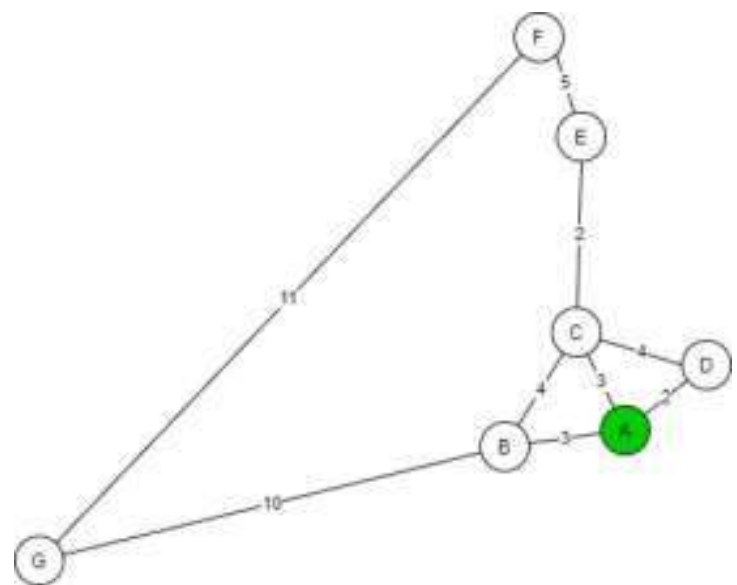

Gambar 2. Waktu tempuh antar titik dalam Graf pada tujuan masjid yang akan dikunjungi

Dalam gambar graf di atas, angka pada garis hubung graf merupakan waktu tempuh yang diperoleh dari data google maps dalam satuan menit. Waktu tempuh menggunakan kendaraan bermotor roda empat dan data diambil pada jam 8 pagi waktu setempat. 


\section{Hasil Penelitian}

Dari data yang diperoleh, maka diasumsikan total alokasi waktu yang dapat dimiliki adalah 8 jam (480 menit) dan asumsi waktu singgah tiap masjid adalah 1 jam (60 menit), maka total hasil tiap titik dari satu masjid ke masjid lainya didapatkan dari total waktu tempuh + total waktu singgah.

Model perhitungan pertama ini menjumlah waktu tempuh dan waktu singgah dari titik awal perhitungan, yaitu dari masjid Al Khairiyah ( titik A). maka perhitunganya adalah sebagai berikut:

$$
\begin{array}{ll}
- & A=>B=3+60=63 \\
- & A=>C=3+60=63 \\
- & A=>D=2+60=62
\end{array}
$$

Dari perhitungan tersebut maka $A \Rightarrow D$ adalah nilai terkecil dan titik D yang dipilih. Maka sisa waktu yang dimiliki menjadi 480$62=418$ menit. Kemudian perhitungan dilanjutkan dari titik $\mathrm{D}$ ke titik yang berhubungan langsung dengan titik tersebut.

$$
\text { - } \quad \mathrm{D}=>\mathrm{C}=4+60=64
$$

Dari perhitungan tersebut maka titik D ke titik $\mathrm{C}$ merupakan satu satunya jalur yang dapat dilewati, sehingga sisa waktu yang dimiliki menjadi 418-64 = 354 menit. Kemudian perhitungan dilanjutkan dari titik $\mathrm{C}$ ke titik yang berhubungan langsung dengan titik tersebut.

$$
\begin{array}{ll}
- & C=>E=2+60=62 \\
- & C=>B=4+60=64
\end{array}
$$

Dari perhitungan tersebut maka $\mathrm{C}=>\mathrm{E}$ adalah nilai terkecil dari titik $\mathrm{C}$ yang dipilih. Maka sisa waktu yang dimiliki menjadi 354$62=292$ menit. Kemudian perhitungan dilanjutkan dari titik $\mathrm{E}$ ke titik yang berhubungan langsung dengan titik tersebut.

$$
\text { - } \quad E=>F=5+60=65
$$

Dari perhitungan tersebut maka titik E ke titik F merupakan satu satunya jalur yang dapat dilewati, sehingga sisa waktu yang dimiliki menjadi 292-65 = 227 menit.
Kemudian perhitungan dilanjutkan dari titik $\mathrm{F}$ ke titik yang berhubungan langsung dengan titik tersebut.

$$
\text { - } \quad F=>G=11+60=71
$$

Dari perhitungan tersebut maka titik $\mathrm{F}$ ke titik $\mathrm{G}$ merupakan satu satunya jalur yang dapat dilewati. Sehingga sisa waktu yang dapat dimilliki menjadi 227-71 = 156 menit. Kemudian perhitungan dilanjutkan dari titik $\mathrm{G}$ ke titik yang berhubungan langsung dengan titik tersebut.

$$
\text { - } \mathrm{G}=>\mathrm{B}=10+60=70
$$

Dari perhitungan tersebut maka titik $\mathrm{G}$ ke titik B merupakan satu satunya jalur yang dapat dilewati dan titik $\mathrm{B}$ merupakan titik terakhir dari semua titik yang belum dikunjungi. Sehingga sisa waktu yang dimiliki menjadi 156-70 = 86 menit.

\section{Kesimpulan}

Dari hasil penelitian tersebut maka dapat disimpulkan rute tercepat untuk mengunjungi semua masjid menggunakan algoritma greedy dimulai titik $\mathrm{A}=>\mathrm{D} \Rightarrow \mathrm{C} \Rightarrow \mathrm{E} \Rightarrow \mathrm{F} \Rightarrow \mathrm{G}$ $\Rightarrow \mathrm{B}$ atau dimulai dari masjid Al Khairiyah ke masjid maninjau dengan total alokasi waktu 62 menit. Setelah itu dilanjutkan dari masjid maninjau ke masjid Syeikh Mahmuddin dengan total alokasi waktu 64 menit. Setelah itu dilanjutkan dari masjid Syeikh Mahmuddin ke masjid Al Khair dengan total alokasi waktu 62 menit. Setelah itu dilanjutkan dari masjid Al Khair ke masjid Al Ma'ruf dengan total alokasi waktu 65 menit. Setelah itu dilanjutkan dari masjid $\mathrm{Al}$ Ma'ruf ke masjid Islamic Center dengan total alokasi waktu 71 menit. Dan jalur terakhir dari masjid Islamic Center ke tujuan terakhir masjid Al Muaawanah dengan total alokasi waktu 70 menit.

Dari hasil penelitian ini juga dapat diperoleh waktu tempuh terpendek yaitu dari titik A ke titik D atau dari masjid Al Khairiyah ke masjid Maninjau dan dari titik C ke titik E atau dari masjid Syeikh Mahmuddin ke masjid Al Khair dengan waktu tempuh 2 menit menggunakan kendaraan mobil. Selain 
itu, diperoleh waktu tempuh terpanjang yaitu dari titik $F$ ke titik $G$ atau dari masjid $\mathrm{Al}$ Ma'ruf ke masjid Islamic Center dengan waktu tempuh 11 menit.

Total durasi waktu perjalanan dan waktu singgah dapat diperoleh dari asumsi alokasi waktu dikurangi sisa alokasi waktu perjalanan. Maka dapat dituliskan 480-86 = 394 menit atau dapat disimpulkan total waktu perjalanan dan waktu singgah adalah 6jam 34 menit dengan durasi singgah tiap masjid yang dikunjungi adlaah 60 menit (1 jam).

Total waktu tempuh titap titik tidak hanya didasari pada jarak, namun juga didasari pada tingkat kepadatan lalu lintas pada jalur tersebut dan hambatan lampu merah yang dilalui. Selain itu juga dipengaruhi oleh hambatan arah satu jalur lalu lintas sehingga sebagai contoh hasil durasi waktu tempuh dari titik F ke titik G tidak sama dengan durasi waktu tempuh dari titik $\mathrm{G}$ ke titik F.

Dalam praktek dikehidupan, algoritma greedy dapat digunakan untuk mencari alternatif jarak tempuh terpendek dalam safari dakwah maupun tujuan lainya yang memerlukan analisa waktu optimal untuk mengunjungi semua masjid yang ada di kota Samarinda.

\section{Saran}

Penelitian ini merupakan langkah awal untuk membantu para ustadz, kyai maupun ulama dalam melakukan safari dakwah, selain itu juga membantu pihak kementerian agama dalam melaksanakan tugas untuk mendata dan melakukan kunjungan ke masjid-masjid yang ada di kota Samarinda. Maka dengan adanya penelitian ini sangat diperlukanya perluasan dalam perhitungan seluruh masjid yang ada di kota Samarinda dengan mempertimbangkan waktu krusial atau waktu tertentu dengan tingkat kepadatan lalu lintas yang tinggi. Selain itu juga perlu adanya pengembangan analisa jumlah waktu singgah tiap tiap masjid yang pada dasarnya waktu singgah tiap masjid seharusnya berbeda beda sesuai dengan kebutuhan pada tiap-tiap masjid yang dikunjungi.

\section{Daftar Pustaka}

[1] Y. Darnita and R. Toyib, "Penerapan Algoritma Greedy Dalam Pencarian Jalur Terpendek Pada Instansi-Instasi Penting Di Kota Argamakmur Kabupaten Bengkulu Utara," vol. 15, no. 2, 2019.

[2] A. M. Herli and I. K. Raharjana, "Sistem Pencarian Hotel Berdasarkan," vol. 1, no. 1, pp. 9-16, 2015.

[3] E. N. Hayati and A. Yohanes, "Pencarian Rute Terpendek Menggunakan Algoritma Greedy," Semin. Nas. IENACO, pp. 2337-4349, 2014.

[4] S. Byun, M. J. Irvin, B. A. Bell, M. J. Irvin, and B. A. B. Advanced, "Advanced Math Course Taking: Effects on Math Achievement and College Enrollment," $J$. Exp. Educ., vol. 83, no. 4, pp. 439-468, 2014, doi: 10.1080/00220973.2014.919570.

[5] A. Juniansyah and Mesterjon, "Aplikasi Penentuan Rute Terpendek Untuk Bagian Pemasaran Produk Roti Surya Dengan Metode Best First Search," Media Infortama, vol. 12, no. 1, pp. 31-40, 2016. 